\title{
Audit of deaths in general practice: pilot study of the critical incident technique
}

\author{
Anita Berlin, John A Spencer, Raj S Bhopal, Timothy D van Zwanenberg
}

\begin{abstract}
Objective - To develop and pilot a method for conducting an audit of deaths in general practice by the critical incident technique.

Design - Prospective use of the technique within a primary health care team, with the aid of a facilitator, to analyse the events surrounding patients' deaths.
\end{abstract}

Setting - One inner city academic general practice.

Participants - Practice team, comprising general practitioners, trainee, practice manager, practice nurse, and attached health visitor and district nurses.

Main measures - Identification and classification of critical incidents associated with the case studies of eight recently deceased patients in the practice and subsequent impact on the practice.

Results - Among the eight case studies, 57 critical incidents were identified (mean $7 \cdot 1$ per case, range 2 to 15). A failure of communication was the most common factor identified in incidents giving rise to concern, but positive factors in patient care were also identified. Changes in practice included developing protocols for follow up of bereaved relatives and carers and $a$ checklist to ensure completion of administrative follow up tasks resulting from the patient's death; cases of recent deaths and terminally ill patients were reviewed monthly. The practice team found the method acceptable and felt that the discussions had provided useful opportunities for reflecting on their role in patient care.

Conclusions - The critical incident technique fulfils the needs of an audit of deaths in general practice; however, further evaluation based on more cases from different practices is now required. (Quality in Health Care 1992;1:231-235)

\section{Introduction}

The analysis of a significant event, such as a patient's death, is a useful approach to medical audit. ${ }^{1}$ Using death as a starting point for auditing patient care has the advantage that it is a universally applicable event that does not require a sophisticated clinical definition. Although a death is a traumatic event for surviving carers and relatives it may also create an opportunity for health workers to reflect on the quality of care provided. Finally, the audit of a death (whether in hospital or in the community) permits a team approach because many members of a team may have played a part in care, particularly of a terminally ill patient.

Among the established, and by acknowledgement, effective, forms of medical audit in the United Kingdom are the confidential inquiries into mortality in the hospital sector. $^{23}$ These are anonymous inquiries judged by external assessors, usually by applying preset criteria. Confidential inquiries have also been proposed as a method for auditing deaths in general practice. ${ }^{4}$

The analysis of problem cases is a popular educational tool in general practice training, and, more informally, primary health care workers tend to analyse significant events such as deaths by relating anecdotes, often in great detail. This tradition of formal and informal case analysis entailing an examination of facts by those who have been involved in providing care is an unstructured form of internal inquiry. However, this does not in itself constitute audit, a point made by the Standing Medical Advisory Committee in its report on audit and quality, in respect of the traditional "interesting case" approach to clinical meetings. ${ }^{5}$

This paper describes a pilot study to develop and test a method for conducting a structured internal audit of deaths of patients in primary health care. The method needed to harness systematically the recollections of health care workers; encourage creative and constructive criticism without seeking to attribute blame; allow general lessons to be drawn from specific cases; provide quick feedback to participants; and permit evaluation of its impact on policy and practice. We thus explored the potential of the critical incident technique and considered its strengths and weaknesses in relation to other approaches for analysing care before and around the time of death. The technique is an objective method of analysing behaviour, developed in the 1950s by Flanagan, an American occupational psychologist. ${ }^{6}$ Critical incidents are collected by asking observers to recall situations in which they were involved that seemed to be valuable examples of good or bad practice. The description of each incident includes details of the setting, what occurred, an account of the outcome, and why practice was judged to be effective or 
ineffective. The technique has been described as the "most successful method for developing taxonomies of clinical competence" ${ }^{7}$ and has been used in various settings. ${ }^{8-12}$ Incidents can be elicited from individuals or, as in this study, from groups.

\section{Methods}

AIMS

We aimed, firstly, at evaluating the applicability and acceptability of auditing the care of patients who had recently died by the critical incident technique. The objective was to identify episodes in the patient's care that had been "critical" - that is, either beneficial or detrimental to the patient or carers - with a view to improving and maintaining the quality of care. Secondly, we aimed at assessing the feasibility of creating a classification of the factors influencing patient care from the data collected.

\section{SETTING}

The study took place in an inner city academic general practice in Newcastle upon Tyne with a list size of approximately 4000 patients. The primary health care team included four part time academic general practitioners, a practice nurse, reception staff, and an attached health visitor and two district nurses. The age and sex profile of the practice population was similar to that of the Newcastle district as a whole, and the crude annual death rate of 12 deaths/1000 patients was about the same as the national rate.

\section{CASE ANAIYSIS}

Meetings were convened by a facilitator who was a research general practitioner (AB) with the help of the practice manager. Usually, two weeks' notice was needed to ensure that all the practice staff (general practitioners, trainee, practice manager, and practice nurse) and community nurses (if they had been involved) could attend.

Eight cases were studied over four months: four were chosen by the practice (cases which had caused concern - for example, a premature death) and four were picked at random by $\mathrm{AB}$ from a total of 24 deaths which occurred during the four months. The medical records of the deceased patients were circulated in advance to those attending the meetings with a brief written summary which included medical and social history; date, place, and cause of death; and health care contacts, investigations, and treatment during the last illness. This allowed participants time to consider the implications of the events being studied.

At the beginning of each meeting the purpose and rules of the discussion were explained. Negative criticism and self criticism were discouraged. The doctor or the nurse who had been most involved gave, firstly, his or her own summary of relevant events underlining "good" incidents; then a summary of those events causing concern; and, finally, recommendations for further action. Other members of the group were then invited to
Case summary including concerns raised by critical incident method and remedial actions

An 89 year old widow died at home and was found by her son, her principal carer. The case was referred to the coroner.

Medical history: housebound owing to osteoarthritis; episode of chest pain one year previously - presumed myocardial infarction managed at home (no electrocardiographic examination performed); recovered fully.

$$
\text { Concerns }
$$

1 Cause of chest pain not confirmed

2 Bereavement follow up not provided for her son, who was registered with another (unknown) practice

3 Cause of death not known by practice as coroner's cases are not notified to general practitioners

4 Hospital referral for hearing aid was not cancelled

5 Fact and cause of death were not recorded in or on medical records

\section{Actions}

1 Review role of electrocardiographic examination in diagnosis of chest pain in elderly patients

2 Clarify role of prophylactic aspirin in elderly patients with ischaemic heart disease

3 Enter carer's full name and general practitioner on geriatric summary

4 Create a checklist for actions to be taken after each death - that is, cancellation of appointments, follow up of carers, request for postmortem report

furnish further details until the picture of events was thought to be complete. Each case required between 20 and 40 minutes for discussion. The role of the facilitator was to clarify individual points, to summarise points, and to encourage the group to reach a consensus. The group was then encouraged to define actions and formulate policies to avoid undesirable events recurring and to promote better care, while emphasising the positive aspects of the case. Discussion thus led to setting standards of practice; this forms the basis of the audit. The box shows a summary of a case, listing both incidents causing concern and actions identified to address them. This apparently unremarkable case - of an 89 year old woman dying at home nevertheless generated a range of concerns.

One or two cases were discussed at each meeting. Discussions were videotaped or audiotaped and transcribed. Written material was anonymised and the tapes were then deleted. Finally, informal feedback (about the acceptability and utility of the method) was elicited from the participants, both during and at the end of the study.

\section{ANALYSIS}

It was not simply the patient's death that constituted a critical incident but anything that the participants felt was either an example of good practice or one which may have given rise to concern about the care the patient received, the quality of the patient's life and death, and the quality of life subsequently for 
surviving relatives or carers. The incidents were identified from the transcriptions and categorised by the research team. With each case new categories and subcategories were derived from the data. This process of developing categories grounded in the data follows the principles laid down by Flanagan and others. ${ }^{6} 12$ This will form the basis of a classification of factors influencing health care around the time of death.

\section{Results}

CRITICAL INCIDENTS

The eight cases generated 57 incidents (mean $7 \cdot 1$ per case, range 2 to 15 ). Ideally, collection of data should have continued until no new categories were generated ${ }^{12}$; with our small number of cases the coding was not complete. None the less, the incidents formed natural clusters. A failure of communication was the most common factor identified in incidents giving rise to concern. Other factors included failure of follow up (for example, after an $x$ ray examination had been requested) and inadequate clinical knowledge and inadequate preventive activities (for example, taking blood pressure and giving antismoking advice). Positive factors included honouring carers' wishes for the patient to die at home and visiting a dying patient in hospital. Table 1 shows two initial categories and associated subcategories of factors causing concern.

EVALUATION OF IMPACT ON PRACTICE

Several changes were introduced in the practice in the nine months after the pilot study, which included introducing a checklist to ensure all necessary administrative tasks were performed after a patient's death and including all recent deaths and terminally ill

Table 1 Example of coding: categories and corresponding subcategories in the classification of factors influencing care around time of death

\begin{tabular}{cl}
\hline \multicolumn{1}{c}{ Categories } & Subcategories \\
\hline Failure of communication & $\left\{\begin{array}{l}\text { General practitioner - patient } \\
\text { General practitioner - team member } \\
\text { General practitioner - general practitioner (on call rota) } \\
\text { General practitioner - relative or carer } \\
\text { General practitioner - hospital } \\
\text { Hospital - general practitioner }\end{array}\right.$ \\
Failure of follow up & $\left\{\begin{array}{l}\text { Investigations } \\
\text { After admission } \\
\text { After discharge } \\
\text { After death (carer or relative) }\end{array}\right.$ \\
\hline
\end{tabular}

patients on the agenda of monthly team meetings. A bereavement protocol for the care of carers was also being drawn up.

Team members were positive about the meetings, and they felt that the meetings had provided a useful opportunity to reflect on their role in patient care. They reported an increased awareness of the problems that may arise around the time of a patient's death.

\section{Discussion}

The critical incident technique seems to provide a method which has potential for auditing individual deaths in general practice. We believe it has methodological advantages over the confidential inquiry. The existing confidential inquiries into avoidable deaths, despite being extremely thorough, are limited by the lack of specific feedback to repondents and the absence of any systematic evaluation of impact on health care. Table 2 compares the features of three different methods of inquiry, which are discussed below.

In confidential inquiries cases are analysed with a detailed anonymised questionnaire which is forwarded to external assessors. These assessors judge whether the quality of patient care deviated from a preset standard and may comment on whether a deviation contributed to the death of the patient. Concerns about alleged subjectivity of some of the assessors' findings ${ }^{13}$ have been addressed by the National Confidential Enquiry into Perioperative Deaths. Specialists have been recruited to discuss cases in groups in order to define and reach agreement by consensus on the presence of avoidable or remediable factors associated with the deaths. ${ }^{14}$

The concept of avoidable death which underpins the existing confidential inquiries is problematic, particularly in the general practice setting, where establishing appropriate standards for different circumstances is not always easy. The case of a woman dying of pre-eclampsia in childbirth or a 45 year old man dying after herniorrhaphy certainly warrants scrutiny, ${ }^{15}$ but what about an 89 year old woman found dead at home by her son or a 55 year old unemployed alcoholic who dropped dead from a heart attack? Can their deaths be seen as a poor outcome of health care? The role of the primary health care team

Table 2 Comparison of features of confidential inquiries and critical incident technique

\begin{tabular}{|c|c|c|c|}
\hline & $\begin{array}{l}\text { Confidential Enquiries into } \\
\text { Maternal Mortality }\end{array}$ & $\begin{array}{l}\text { National Confidential Enquiry } \\
\text { into Perioperative Deaths } 1990^{14}\end{array}$ & Critical incident technique \\
\hline Type of audit & External & External & Internal \\
\hline Assessors & $\begin{array}{l}\text { Experts from specialty or } \\
\text { related specialty }\end{array}$ & Small group of peers & Primary health care team \\
\hline Method of case analysis & $\begin{array}{l}\text { Independent review of } \\
\text { questionnaire }\end{array}$ & $\begin{array}{l}\text { Semistructured facilitated } \\
\text { discussions by assessors of } \\
10 \% \text { of reported cases after } \\
\text { review of questionnaires }\end{array}$ & $\begin{array}{l}\text { Semistructured facilitated } \\
\text { discussion of cases by the team } \\
\text { who provided primary care }\end{array}$ \\
\hline $\begin{array}{l}\text { Quality criteria for } \\
\text { setting standards and } \\
\text { coding }\end{array}$ & $\begin{array}{l}\text { Implicit or explicit according } \\
\text { to preset criteria }\end{array}$ & $\begin{array}{l}\text { Generally implicit, grounded in } \\
\text { the data from this and previous } \\
\text { inquiries }\end{array}$ & Implicit, grounded in the data \\
\hline $\begin{array}{l}\text { Feedback and } \\
\text { dissemination of findings }\end{array}$ & $\begin{array}{l}\text { Passive, non-specific; triennial } \\
\text { reports widely available }\end{array}$ & $\begin{array}{l}\text { Passive, recommendations in } \\
\text { published reports }\end{array}$ & $\begin{array}{l}\text { Active and immediate only } \\
\text { within team }\end{array}$ \\
\hline $\begin{array}{l}\text { Evaluation of impact on } \\
\text { individual }\end{array}$ & $\begin{array}{l}\text { Not undertaken; restricted by } \\
\text { confidentiality }\end{array}$ & $\begin{array}{l}\text { Not undertaken; restricted by } \\
\text { confidentiality }\end{array}$ & $\begin{array}{l}\text { Implementation of agreed actions } \\
\text { being evaluated }\end{array}$ \\
\hline
\end{tabular}


in these people's lives may be far more important than any contribution around the time of their deaths. By what criteria do we decide whether there were avoidable factors?

Those involved in the care of such patients are best able to answer these questions, and there is evidence that participating in setting standards is more likely to lead to change in behaviour than simply receiving preset guidelines. ${ }^{16}$ The formation of group practices and primary health care teams emphasises the need for health professionals to communicate and collaborate and should enable collective internal analysis of problems. The critical incident technique provides a means for improving team care by which teams can set their own standards and agree the changes that need to be implemented, appropriate to their needs and in a supportive environment. All involved can contribute and learn.

The need to maintain confidentiality through anonymity in external audits is regarded as paramount. Anonymity encourages reporting without fear of ascribing blame to the respondents. This does mean, however, that little feedback is available for individuals. The maternal mortality inquiries made no attempt to provide feedback other than by the recommendations in their triennial reports. Recognising this limitation the first Confidential Enquiry into Perioperative Deaths $^{13}$ provided optional access for respondents to the scores awarded by the inquiry's assessors. However, only $5 \%$ of respondents ever sought their scores. It is not known why there was such little interest, but other work supports the concerns of the inquiry's authors ${ }^{14}$ and others ${ }^{17}$ that "passive feedback", unsupported by evaluative or educational initiatives, has limited impact on clinical behaviour. ${ }^{18}$ This may be compounded by the long delay between case reporting and publication of findings. The longer the time between the event and the feedback the smaller the impact on practice. ${ }^{19}$ The technique we describe avoids this problem.

Finally, the existing confidential inquiries, for reasons of legality and confidentiality, do not lend themselves to evaluation of their impact. Although their influence on clinical practice is rarely questioned, it is difficult to prove their effectiveness or explain why and how some doctors' practice is influenced. Consecutive inquiries have shown reduced mortality rates, but it is impossible to determine whether the surveys are accelerating this process or merely describing it. ${ }^{20}$

The key differences between the critical incident technique and the existing model of confidential inquiry are that the critical incident technique is internal audit (by the team, of the team); criteria are not preset but are implicit to each case; feedback is immediate; and specific evaluation of impact on individuals may be possible. Most importantly, we have found that change has resulted from setting standards during the case analysis, although whether these changes are maintained in the long term will require further study.
The method has certain limiting factors. Some primary care teams may not be comfortable with the emotional content which accompanies the frank discussion of events around death. For example, one of the cases discussed in the pilot study involved a man who died from a cerebral tumour in his early 40s. The discussion highlighted the unresolved grief of one of the nurses who had looked after him, which could have caused feelings of discomfort. The discussions are also time consuming and may place considerable demands on both group skills and the skills of inductive reasoning of team members. ${ }^{21}$ In this respect, a facilitator may be more or less crucial, depending on the skills of the team. Mechanisms are also needed to ensure that adequate information about the deaths of all patients is readily available to primary health care teams. ${ }^{22}$ Finally, discussions must be kept strictly confidential and written details must be anonymised.

The search for avoidable factors in individual deaths has been described as "perhaps the most stringent form of self criticism to any clinical team." 23 We would add that analysing individual deaths can disclose important areas where the process of care can be improved even when the outcome (death) is not amenable to intervention by health care professionals.

We believe that the critical incident technique fulfils the needs of a method for audit of deaths in general practice. We are now proceeding to the main study to evaluate the method in terms of selection of cases, changes in policy, organisation, professional practice, and the role of the facilitator.

We thank all the members of the primary health care team at Adelaide Medical Centre, Benwell, Newcastle upon Tyne; Dr Rebecca Wagstaff for her helpful work on the drafts of the manuscript; and Ms Sharon Campan for her invaluable secretarial expertise. This project is funded by a grant from the Department of Health.

1 Buckley G. Clinically significant events. In: Marinker $M$, ed. Medical audit in general practice. London: MSD Foundation, 1990:144-67.

2 Department of Health. Reports on confidential enquiries into maternal mortality 1982-4. London: HMSO, 1989.

3 Campling EA, Devlin HB, Lunn JN. Report of the national confidential enquiry into perioperative deaths 1989. London: confidential enquiry into perioperative deaths 1989. London:
NCEPOD, 1990 .

4 Irvine DH, Irvine S, eds. Making sense of audit. Oxford: Radcliffe Medical, 1991 .

5 Standing Medical Advisory Committee. The quality of medical care. London: HMSO, 1990.

6 Flanagan JC. The critical incident technique. Psychol Bull 1954;51:327-58

Critical questions; critical incidents; critical answers. Lancet 1988;i:1373-4.

8 Newble D. The evaluation of clinical competence. Med $f$ Aust 1976;2:180-3.

9 Bradley CP. Uncomfortable prescribing decisions: a critical incident study. $B M \mathcal{F}$ 1992;304:294-6.

10 Waterston T. A critical incident study in child health. Med Educ 1988;22:27-31.

11 Gau D, Pryce Jones M, Tippins D. Satisfactory practice. Health Service fournal 198930 November:1163-4.

12 Strauss AL. Qualitative analysis for social scientists. New Yrauss AL. Qualitative analysis for social

13 Buck N, Devlin HB, Lunn NN. Report of the confidential enquiry into perioperative deaths. London: Nuffield Provincial Hospital Trust and King's Fund, 1987.

14 Campling EA, Devlin HB, Hoile RW, Lunn JN. Report of the national confidential enquiry into perioperative deaths 1990. London: NCEPOD, 1992.

15 Rutstein DD, Berenberg W, Chalmers TC, Child CG, Fishman AP, Perrin EB. Measuring the quality of medical care. New Engl f Med 1976;29:582-8. 
16 North of England Study of Standards and Performance in General Practice. Medical audit in general practice. I. Effects on doctors' clinical behaviour for common childhood conditions. BMf 1992;304:1480-4.

17 NCEPOD strikes again. Lancet 1992;339:1025.

18 Mitchell MW, Fowkes FGR. Audit reviewed: does feedback on performance change clinical behaviour? $\mathfrak{f} R$ Coll Physicions

19 Mugford M, Banfield P, O'Hanlon M. Effects of feedback of information on clinical practice: a review. $B M \mathcal{F}$ 1991;303:398-402.
20 Shaw C. Perioperative and perinatal death as measures of quality assurance. Quality Assurance in Health Care 1990;2:235-41.

21 Bradley CP. Turning anecdotes into data - the critical incident technique. Fam Pract 1992;9:98-103.

22 Berlin AP, Bhopal RS, Spencer JA, van Zwanenberg TD. Dying to know: creating death registers for general practice. $\mathrm{Br} \mathcal{f}$ Gen Pract (in press)

23 Hart JT, Humphreys C. Be your own coroner: an audit of 500 consecutive deaths in a general practice. $B M \mathcal{F}$ 1987;294:871-4. 